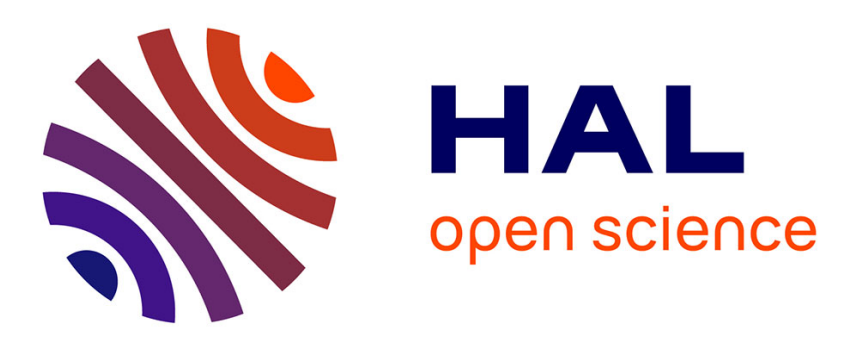

\title{
Enzymatic synthesis of a series of thioglycosides: Analogs of arbutin with efficient antipigmentation properties
}

Cedric Peyrot, Blanka Didak, Laure Guillotin, Ludovic Landemarre, Pierre Lafite, Loic Lemiegre, Richard Daniellou

\section{To cite this version:}

Cedric Peyrot, Blanka Didak, Laure Guillotin, Ludovic Landemarre, Pierre Lafite, et al.. Enzymatic synthesis of a series of thioglycosides: Analogs of arbutin with efficient antipigmentation properties. European Journal of Organic Chemistry, 2021, 2021 (27), pp.3812-3818. 10.1002/ejoc.202100672 . hal-03331379

\author{
HAL Id: hal-03331379 \\ https://hal.science/hal-03331379
}

Submitted on 7 Sep 2021

HAL is a multi-disciplinary open access archive for the deposit and dissemination of scientific research documents, whether they are published or not. The documents may come from teaching and research institutions in France or abroad, or from public or private research centers.
L'archive ouverte pluridisciplinaire HAL, est destinée au dépôt et à la diffusion de documents scientifiques de niveau recherche, publiés ou non, émanant des établissements d'enseignement et de recherche français ou étrangers, des laboratoires publics ou privés. 
WILEY-VCH

\title{
Enzymatic synthesis of a series of thioglycosides, analogs of arbutin, owing efficient antipigmentation properties
}

\author{
Cédric Peyrot ${ }^{[a, b, 1]}$, Blanka Didak ${ }^{[c]}$, Laure Guillotin ${ }^{[a]}$,Ludovic Landemarre ${ }^{[c]}$, Pierre Lafite ${ }^{[a]}$, Loïc \\ Lemiègre $^{[b]}$, Richard Daniellou*[a]
}
[a] Dr. C. Peyrot, Dr. L. Guillotin, Dr. P. Lafite, Prof. Dr. R. Daniellou
Institut de Chimie Organique et Analytique (ICOA) - UMR CNRS 7311, University of Orléans
Rue de Chartres, BP6759, 45067 Orléans cedex 2, France
E-mail: richard.daniellou@univ-orleans.fr; http://www.icoa.fr/en/daniellou
[b] Dr. C. Peyrot, Dr. L. Lemiègre
Univ Rennes, Ecole Nationale Supérieure de Chimie de Rennes, CNRS, ISCR - UMR6226, F-35000 Rennes, France.
[c] Dr. B. Didak, Dr. L. Landemarre
GLYcoDiag
2 rue du cristal, 45100 Orléans, France
${ }^{1}$ Present addresse: URD Agro-Biotechnologies Industrielles, CEBB, AgroParisTech, 51110 Pomacle, France;

Supporting information for this article is given via a link at the end of the document

\begin{abstract}
Arbutin, a natural glycoside, is well known as a commercial tyrosinase inhibitor and thus to prevent pigmentary disorders of skin. Indeed, tyrosinase is involved in the biosynthesis of melanin, the skin main pigment. However, arbutin is subject to hydrolysis, which limits its bioactivity. In general, thioglycosides are known to be very resistant to both chemical and enzymatic hydrolysis, which increases the interaction time with their biological targets. A biocatalytic approach allowed us to access to thioglycosidic analogs of arbutin in a green approach with good to excellent yields. Such compounds have then been tested as tyrosinase inhibitors and also as inhibitors of melanin transfer from melanocytes to keratinocytes. This latter mechanism takes place via lectin (or lectin-like) receptors present on the cells surface. p-Aminophenyl ß-D-thiogalactopyranoside appears to be an excellent candidate thanks to its tyrosinase inhibitory activity comparable to arbutin, while having the ability to interact with glycan receptors allowing to reduce melanin transfer.
\end{abstract}

\section{Introduction}

Due to the global warming, the world population is more and more exposed to the sun, thus leading to a continuous rise in the appearance of skin pigmentary disorders. One of them, namely hyperpigmentation, is generally due to a local overproduction of melanin correlated to a significant increase of melanosome number in the epidermis. However, sun exposure is not the only external parameter, and hormonal or contraceptive treatments can also trigger this kind of disorders. To limit these unsightly aspects, there are common physical or chemical skin treatments ${ }^{[1]}$, but other approaches have been also developed, including melanin transfer inhibition from melanosomes to keratinocytes, melanosomes alteration or inhibition of the DNA transcription coding for tyrosinase ${ }^{[2]}$. Some chemical treatments, notably hydroquinone ${ }^{[3]}$, have effects on these targets (Figure 1 ). It has been part of the reference molecules as whitening agent for more than 50 years. However, its significant side effects like irritation or itch phenomena, have led to its disappearance in cosmetic products ${ }^{[4]}$. Indeed, its oxidation leads to quinones formation and generation of free radicals which can cause cell membrane alterations and induce the effects mentioned above ${ }^{[5]}$. To restrict these side-effects, manufacturers have turned their attention to hydroquinone analogs, with one protected phenolic moiety, such as mequinol or monomethyl ether of hydroquinone (MMEH) ${ }^{[4 a]}$. Nevertheless, the current best alternative is the use of its $\beta$ glucosylated substituent, namely arbutin (Figure 1). This natural compound is extracted from the leaves and barks of many plants such as bearberry ${ }^{[6]}$. The presence of the glucosyl moiety increases its water solubility while retaining a good antipigmentation activity ${ }^{[7]}$. In addition, this molecule has the advantage of being less toxic to cells. Moreover, glycoconjugates are described as being capable to interact with the membrane receptors present on the cell surfaces (lectins) thanks to their sugar moiety so as to inhibit the melanin transfer from melanocytes to keratinocytes ${ }^{[8]}$ (Figure 2)

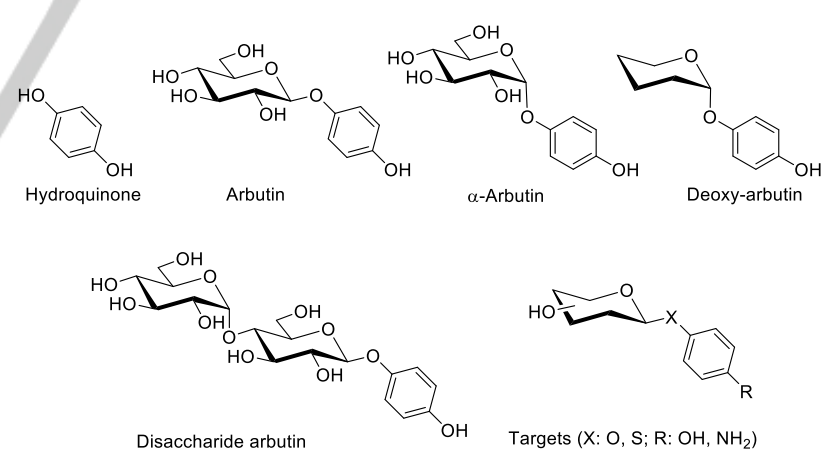

Figure 1: Hydroquinone and Arbutin analogues 


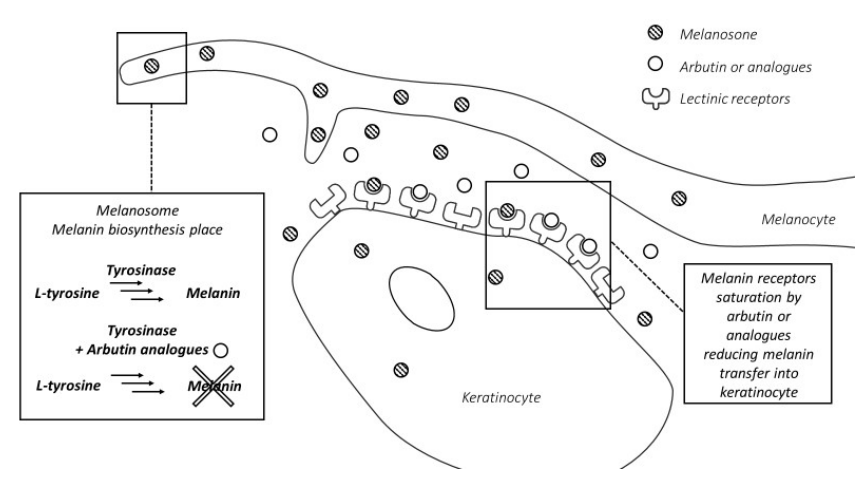

Figure 2: Tyrosinase and melanine transfer inhibitions.

In an attempt to obtain improved tyrosinase inhibitors, various arbutin analogs have been proposed, i.e. $\alpha$-arbutin, deoxy-arbutin or analogs in the form of disaccharides ${ }^{[9]}$. All these glycosides present interesting properties but, in all the cases mentioned above, their chemical and/or enzymatic hydrolysis leads to hydroquinone release, which might cause serious skin disorders. The use of a thioglycoside, more resistant against chemical or enzymatical hydrolysis, would limit the hydroquinone release while retaining biological activities ${ }^{[10]}$. Thioglycoconjugates are already commonly used as stable ligands for the crystallographic analysis of protein structures or as glycosidase inhibitors ${ }^{[11]}$. They can even serve for the development of carbohydrate-based vaccine antigen ${ }^{[12]}$.Until recently, their only access was through very tedious chemical synthesis steps ${ }^{[13]}$, or through metallic catalysis reactions ${ }^{[14]}$, in particular because of numerous protection and deprotection steps ${ }^{[15]}$, thus limiting drastically the commercial applications. One solution to overcome this limitation relies in the use of enzymatic synthesis, which in addition will owe the advantage of decreasing environmental impact ${ }^{[16]}$. In 2003, Withers et al described a major advance in terms of thioglycoconjugates synthesis by proposing the first enzymes capable to promote the formation of this type of linkage ${ }^{[17]}$, a biocatalyst obtained thanks to judicious mutations on the acid/base residue of the catalytic site starting from a native glycosidase ${ }^{[18]}$. With a similar approach based on site-directed mutagenesis, our group has been able to access to a novel thioglycoligase (DtGlyE159Q) from Dictyoglomus thermophilum ${ }^{[19]}$. In particular, this mutant, whose hydrolytic activity has been greatly reduced by the replacement of the catalytic E159 by a glutamine, has the capacity to efficiently catalyze the binding of a saccharidic unit on thiophenolic $\begin{array}{llll}\text { derivatives, } & \text { which } & \mathrm{pKa} & \text { (around }\end{array}$ (https://doi.org/10.1021/ja058344i)) is of high importance to lead to very good reaction yields.

Herein, we thus wish to report the efficient biocatalyzed synthesis of numerous $S$-arbutin analogs and their biological properties as promising whitening agents. We therefore focused on cosmetic alternatives that rely on tyrosinase inhibition at the melanosome level and therefore prevent the synthesis of melanin ${ }^{[20]}$.

\section{Results and discussion}

1) Biocatalyzed synthesis
In order to obtain arbutin analogs, we particularly focused on thiophenolic compounds, which could mimic hydroquinone. First, to keep a good analogy, our choice fell on $p$-hydroxythiophenol, as well as $p$-aminothiophenol to rule on the phenolic moiety influence on the biological activities (Scheme 1). Second, the acid/base catalytic residue being mutated, it was essential to use activated sugars to carry out the enzymatic glycosylation step. For this, we chose $p$-nitrophenyl-ß-D-glucopyranoside ( $p$ NPGlc) as sugar donor. In order to favor the nucleophilic attack of sulfur moiety on the glycosyl-enzyme complex, we kept the $\mathrm{pH}$ of the reaction buffer fixed at 9 (Tris- $\mathrm{HCl}, 20 \mathrm{mM}$ ), so that thiophenol acceptors were mostly present in their thiophenolate forms. The reactions were thus carried out and followed by TLC. $p$ Hydroxythiophenol did not react, as only starting material could be detected after enzymatic incubation. This absence of reactivity was thought to be related to the formation of unreactive quinone. Regarding $p$-aminothiophenol acceptor, a new glucosylated compound $S-1$ was detected and, after purification, characterized by NMR. We therefore sought to optimize the enzymatic thioglycosylation reaction based on the same conditions as those used previously. The examples present in the literature highlight the necessity to use a large excess of acceptor equivalents ${ }^{[21]}$. Thus, we initially decided to carry out the reaction in the presence of 40,30 and 20 eq of acceptors (Table 1 entries 1-3) and we did not observe any degradation of the enzyme due to the acceptor under the thiol or disulfide forms.

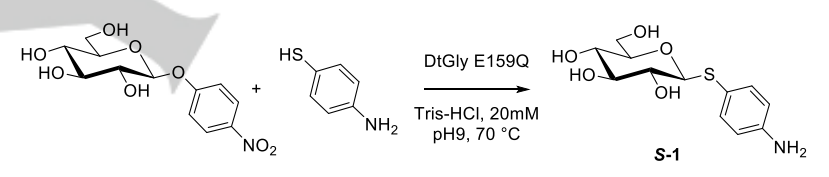

Scheme 1: Enzymatic thioglycosylation scheme

Table 1. Optimization of enzymatic thioglycosylation conditions

\begin{tabular}{ccccccc}
\hline \multirow{2}{*}{ Entry } & \multicolumn{2}{c}{$p$ NPGlc } & Acceptor & DtGly E159Q & Time & Yield \\
& $m g$ & $m m o l$ & Eq & Eq & $(\mathrm{h})$ & $(\%)$ \\
\hline 1 & 40 & $1.310^{-1}$ & 40 & $2.910^{-5}$ & 48 & $75^{\mathrm{a}}$ \\
2 & 40 & $1.310^{-1}$ & 30 & $2.910^{-5}$ & 48 & $69^{\mathrm{a}}$ \\
3 & 40 & $1.310^{-1}$ & 20 & $2.910^{-5}$ & 48 & $82^{\mathrm{a}}$ \\
4 & 40 & $1.310^{-1}$ & 20 & $1.410^{-4}$ & 24 & $99^{\mathrm{a}}$ \\
5 & 40 & $1.310^{-1}$ & 10 & $1.410^{-4}$ & 24 & $92^{\mathrm{a}}$ \\
6 & 40 & $1.310^{-1}$ & 5 & $1.410^{-4}$ & 24 & $82^{\mathrm{a}}$ \\
7 & 100 & $3.310^{-1}$ & 5 & $8.410^{-5}$ & 24 & $91^{\mathrm{a}}$ \\
8 & 600 & 2.0 & 5 & $8.410^{-5}$ & 24 & $96^{\mathrm{a}}$
\end{tabular}

[a] Isolated yields after column purification step

The yields obtained after purification demonstrated that an excess of acceptor caused a negative effect, with 20 eq. leading to the best yield (Table 1, entries 1-3). In parallel, the reaction time, initially set at 48 hours, was reduced to 24 hours. In addition, to limit the potential negative impact of this reduction time, the 
quantity of enzyme was multiplied by 5 . The reactions were carried out under these conditions in the presence of 20,10 and 5 equivalents of acceptor (Table 1, Entries 4-6). Indeed, when the number of acceptor equivalents decreased, so did the yield. However, the conditions of entry 4 allowed an optimized yield of $99 \%$ in just 24 hours. The increase of the quantity of enzyme had a very positive effect on the reaction, while remaining in catalytic quantity. In addition, when the acceptor equivalents decreased, we still kept excellent yields (Table 1, Entries 5-6: 92\% and $82 \%$, respectively). Two stages of gradual scale up were carried out, starting from $100 \mathrm{mg}$ and then $600 \mathrm{mg}$ of sugar donor (Table 1, Entries 7-8). The yields being good in 24 hours on small quantities, we tried to reduce by 1.7 the enzyme equivalents for the scaling up reaction. The yields obtained for both conditions were very good with respective values of $91 \%$ and $96 \%$. Under these conditions, they were even quite higher than those obtained previously while the amount of enzyme has been reduced. At this stage, we were therefore able to significantly optimize the reaction by reducing the number of acceptor equivalents required while retaining excellent yields. The reaction time has also been reduced and the enzyme quantity fine-tuned.

We then sought to obtain analogues of molecule $S-1$ carrying different saccharidic moieties. In the literature, numerous glycosidases are described as being versatile with respect to their substrate ${ }^{[22]}$. We therefore carried out the same reaction according to the best conditions (Table 1, Entry 4) starting from different activated sugar donors. The results obtained are presented in Table 2 and Figure 3A.

Table 2. Exemplification of the method starting from different sugar donors ( $p$ NP sugar $0.13 \mathrm{mmol}, p$-aminothiophenol 20 eq, DtGlyE159Q $1.10^{-4}$ eq, $24 \mathrm{~h}, \mathrm{pH} 9$ (Tris- $\mathrm{HCl}, 20 \mathrm{mM}$ ), RT)

\begin{tabular}{clcc}
\hline Entry & Abbreviations & Donors & Yield \\
\hline 1 & $p$ NP-Gal & $p$-nitrophenyl-ß-D-galactopyranoside & $79 \%^{\text {a }}$ \\
2 & $p N P$-Fuc & $p$-nitrophenyl-ß-D -fucopyranoside & $52 \%^{a}$ \\
3 & $p N P$-Xyl & $p$-nitrophenyl-ß-D -xylopyranoside & - \\
4 & $p N P$-GlcA & $p$-nitrophenyl-ß-D-glucuronic acid & - \\
\hline
\end{tabular}

[a] Isolated yields after column purification step

The enzyme accepted other sugar donors. Its versatility allowed us to obtain compound $\mathbf{S}-\mathbf{2}$ carrying a D-galactosyl unit, with a good yield of $79 \%$ (Table 2, Entry 1 ) as well as compound $\mathbf{S}-3$ in D-fucose series with a lower yield of $52 \%$ (Table 2, Entry 2). Unfortunately, the enzymatic reaction did not occur in presence of pNP-Xyl or pNP-GlcA (Table 2, Entries 3-4).

Finally, we were also wondering whether the nature of the glycosidic linkage could also have an effect on anti-pigmentation activity. Using a simple and rapid methodology, already published by Peyrot et al, we were able to quickly access the p-aminophenyl ß-D-glycopyranosides from the corresponding pNP sugars, by reduction of the nitro moiety without any protection or deprotection steps $^{[23]}$. The protocol was developed in presence of dithiothreitol (DTT) in methanol under microwave activation for $2 \mathrm{~h}$. This quick methodology provided access to compounds $\mathbf{0 - 1}, 0-2$ and $0-3$
(Figure 3B) with very good respective yields of 97,91 and $92 \%$ [23]

This allowed us to obtain a library of 8 arbutin analogs in S- or Oglycosidic series carrying different substituents on the aromatic ring (Figure 3). We were then able to assess the anti-pigmentation activity of these 7 compounds on different targets. To compare with arbutin, S-arbutin was synthesized using the methodology developed by Brachet et al through nickel catalysis allowing to access to the perfect analog with a thioglycosides linkage ${ }^{[14 a]}$.
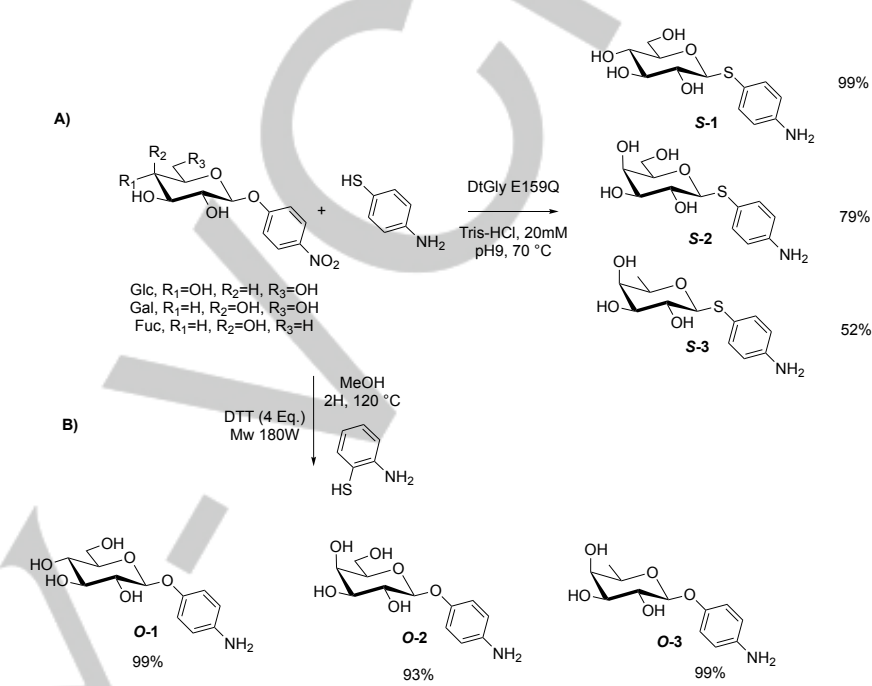

Figure 3. Target molecules for biological evaluations.A) this study. B) Peyrot et al. [23]

2) Tyrosinase inhibition.

According to the targeted mechanism intended to decrease pigmentation, various types of approaches exist to evaluate the anti-pigmentation activity. The simplest and most common is to assess tyrosinase inhibition, the enzyme producing melanin in melanosomes. Based on a protocol described by Masamoto et al., we were able to perform in-vitro inhibition studies for each molecule ${ }^{[24]}$. The enzymatic activity was monitored by spectrophotometry and the $\mathrm{IC}_{50}$ values were recovered with GraphPad. The $\mathrm{IC}_{50}$ correspond to the concentrations needed to observe $50 \%$ of activity loss. All the data have been grouped in Table 3, and arbutin was used as the positive control.

Table 3. Tyrosinase inhibition $\mathrm{IC}_{50}$ for each arbutin analog according to the Masamoto protocol[24]

\begin{tabular}{cc}
\hline Compounds & $\mathrm{IC}_{50} \mathrm{mM}$ \\
\hline Arbutin & $0.5 \pm 0.8$ \\
S-Arbutin & $0.3 \pm 0.7$ \\
S-1 & $2.0 \pm 0.7$ \\
S-2 & $0.7 \pm 0.8$ \\
S-3 & $4.1 \pm 0.5$ \\
O-1 & $2.4 \pm 0.8$
\end{tabular}


$0-2$

$2.6 \pm 0.8$

$0-3$

$2.9 \pm 0.8$

The $\mathrm{IC}_{50}$ values mentioned in the literature are somehow variable depending on the natural source of the tyrosinase but remain in the order range of $\mathrm{mM}^{[9 a, 9 b]}$. Our experimental value for arbutin was therefore in agreement with the literature, which thus validates the experimental protocol. The glycosidic linkage nature, the sugar moiety as well as the substitution on the aromatic ring may have an influence on the inhibition activity of tyrosinase. When we focused on the influence of nature of the aromatic cycle, it appeared that the phenolic group led overall to better tyrosinase inhibition (Table 3, Arbutin vs $\mathbf{0 - 1}$ ). The nature of the sugar also demonstrated an important influence. Indeed, the presence of a fucose was unfavorable (Table 3, Compound S-3) whereas the presence of a galactose unit made it possible to gain in efficiency (Table 3, Compound S-2). In the case of galactose, the presence of the sulfur atom even made it possible to obtain a more effective molecule (Compounds $\mathbf{S - 2}$ and $\mathbf{0 - 2}$ ). At this stage, the compound S-2 appeared as the best candidate, both regarding its $\mathrm{IC}_{50}$ value but also its stability against hydrolysis. Considering the first results, and the low activity differences regarding tyrosinase inhibition between $S$-arbutin and compound $\mathbf{S}-\mathbf{2}$, we have chosen to focus on the latter, obtained by a biocatalysed procedure.

3) Lectin recognition.

We then investigated the potency of inhibition of melanin transfer from melanocytes to the keratinocytes by the compounds. This process takes place through the activation of lectin-type receptors on the cell surface ${ }^{[8 a]}$. These lectins are capable of specifically recognizing glycan motifs, then triggering the migration process of melanin. The aim of this study was to consider the influence, or not, of the sulfur atom at the level of the sugar linkage. Given the promising in vitro results obtained for the compound S-2, we carried out this recognition test with this compound as well as its analogue in $\mathbf{O}$-series $\mathbf{0 - 2}$. To assess whether these new molecules can potentially be recognized by lectin-like receptors involved in melanin transfer (expressed at the surface of melanosomes and/or keratinocytes), we first set up in vitro screening on different lectins based on the GLYcoPROFILE $®$ technology described by Landemarre et al ${ }^{[25]}$. The specificity and the nature of each lectin are reported in the supporting information. Lectin recognition tests were carried out in a 96-well plate (LEctPROFILE® plates). Compounds S-2\&O-2 were assessed for their ability to competitively displace the reference labelled ligand for each lectin. In that case, absorbance or fluorescence reads made it possible to determine the percentage of resulting bound reference ligands, bearing either a chromophore or a fluorophore. The results obtained for compound $\mathbf{S - 2}$ and $\mathbf{0 - 2}$ are respectively presented in Figure 4.

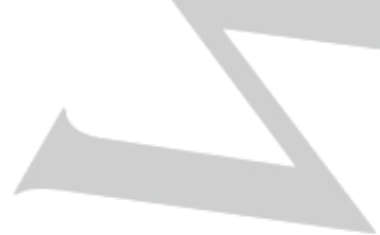

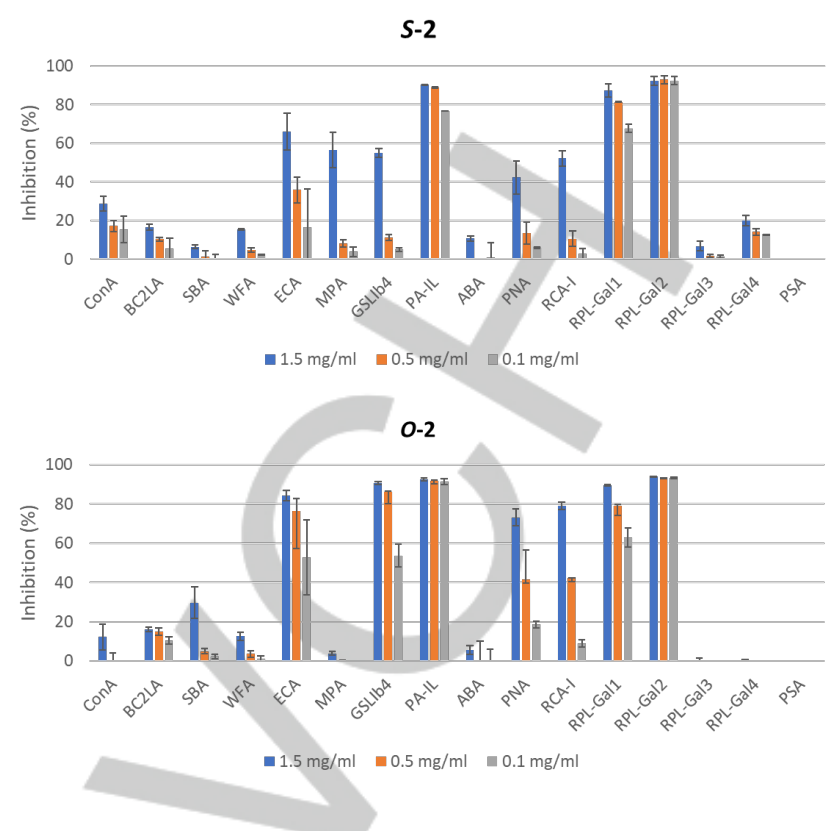

Figure 4. GLYCOPROFILE of compounds $\mathbf{S - 2}$ and $\mathbf{0 - 2}$ at different concentrations

First, it appeared clearly that both compounds $\mathbf{S - 2}$ and $\mathbf{0 - 2}$ were perfectly recognized by the lectins specific for Gal and/or GalNAc motifs. The sulfur atom did not disturb osidic recognition from a global point of view, as both compounds $\mathbf{0 - 2}$ and $\mathbf{S - 2}$ are roughly recognized by the same set of lectins and not recognized similarly by the others. Moreover, the interaction of the lectins seems better with $\mathbf{0 - 2}$ compound than with $\mathbf{S}-\mathbf{2}$ and more specifically regarding the lectins ECA, PA-IL, PNA and RCA-I. The other important element was the preservation of a dose effect. In fact, when the inhibitor molecule was introduced in higher quantity, the binding percentage to receptors was greater, regardless the glycosidic linkage nature. Thioglycosides therefore seemed to be an excellent alternative for inhibiting the melanin transfer.

We further moved to in vitro tests on cell culture. In order to study and compare the potential interaction of $\mathbf{S}-\mathbf{2}$ and $\mathbf{0 - 2}$ compounds with lectin-like receptors expressed at the surface of keratinocytes, we use the method of "neoprofile". A set of fluorescent neoglycoproteins (galactosylated, glucosylated and rhamnosylated) well known to interact in a "glycan-specifically" manner with the surface of normal human epidermal keratinocytes (NHEK) were incubated with the cells in the presence or not of the compounds. After washing, the resulting inhibition of neoglycoprotein shows the specificity of interaction of the corresponding compound. The binding percentage was indirectly measured through the ratio between the studied mixture fluorescence and the reference binding fluorescence. According to cell toxicity up to $1 \mathrm{mg} / \mathrm{mL}$ (determined by MTT test on same keratinocytes, data not shown), we chose to fix this concentration as the cell maximum concentration for the following studies. Several lower concentrations were then tested depending on the compounds. Thus, the higher inhibition percentage results in better compound recognition (Figure 5). 


\section{$S-2$}

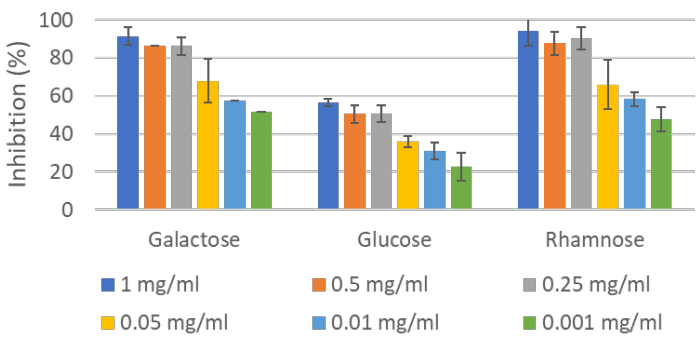

$0-2$

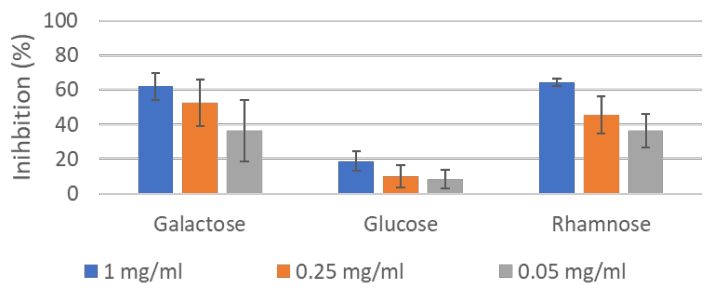

Figure 5. Dose-dependent inhibition by $S-2$ and $0-2$ of carbohydrate-specific lectins on NHEK cells.

Regarding the galactose lectins, the S-2 compound showed better inhibition than $\mathbf{0 - 2}$, and therefore, the binding intensity (inhibition percentage) was markedly greater in the case of compounds carrying a thioglycosidic linkage, suggesting a nature bond positive effect on the cellular interaction. Looking at the other lectins (glucose, rhamnose), once again the $\mathbf{S - 2}$ interacted stronger with the other receptors than the $\mathbf{0 - 2}$. Overall, the presence of a thioglycosidic bond was favorable. However, it induced a slight loss of sugar specificity. This is not necessarily negative in our case, because it would allow better saturation of the various cell receptors to limit the transfer of melanin. In addition, the dose effect was retained significantly. In view of the literature which indicates that the melanin transfer from the melanosome to the keratinocyte can be inhibited by galactosylated or approximate structures ${ }^{[8]}$, the compound $\mathbf{S - 2}$ could be used at a concentration much lower than that of the compound $\mathbf{0 - 2}$.

\section{Conclusion}

We have developed an original approach through enzymatic catalysis allowing access to arbutin analogs with very good yields. One of the best tyrosinase inhibitor was found to be compound $\mathbf{S}$ 2, a thiogalactoside. The molecular and cellular in vitro studies demonstrated a conservation of the osidic specificity of thioglycosides recognized by lectin-like as cell membrane receptors. In addition, the presence of the sulfur atom increased this recognition, while retaining the dose effect. The stability of the compound also gave it a longer lifespan and therefore a longer interaction with the receptors. This made it a double action compound, obtained by an eco-responsible process with high application potential in cosmetics.

\section{Experimental Section}

\subsection{Chemical synthesis}

p-Nitrophenyl-ß-D-glucopyranoside, $p$-nitrophenyl-ß-D-galactopyranoside, $p$-nitrophenyl- $ß$-D-fucopyranoside, $p$-nitrophenyl- $ß-D$-xylopyranoside, $p$ -

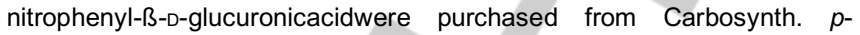
Aminothiophenol, $p$-hydroxythiophenol and arbutin were purchased from Sigma Aldrich. All chemicals were used directly without purification. Chromatographic purifications of products were accomplished using a silica column in dichloromethane/methanol eluent. ${ }^{1} \mathrm{H}$ NMR spectra were recorded on Avance III HD NanoBay Bruker at $400 \mathrm{MHz}\left({ }^{13} \mathrm{C}: 100 \mathrm{MHz}\right)$ and were calibrated with residual $\mathrm{D}_{2} \mathrm{O}$ or $\mathrm{CD}_{3} \mathrm{OD}$ protons signals at $\delta 4.79$ or $3.31 \mathrm{ppm}$ respectively. Data are reported as follows: chemical shift $(\delta$ ppm), multiplicity ( $s=$ singlet, $d=$ doublet, $t=$ triplet, $d d=$ doublet of doublet, $\mathrm{m}=$ multiplet), coupling constant $(\mathrm{Hz})$, integration and assignment. ${ }^{13} \mathrm{C}$ NMR spectra were calibrated with $\mathrm{CD}_{3} \mathrm{OD}$ signal at $\delta 49.2 \mathrm{ppm}$. Data are reported as follows: chemical shift ( $\delta \mathrm{ppm})$ and attribution. All NMR assignments were made using COSY, HMBC and HSQC spectra. HRMS were performed on a Maxis Bruker $4 \mathrm{G}$ system.

\section{Chemical thioglycosylation}

p-Hydroxyphenyl-ß-D-glucopyranoside (S-arbutin) was synthesized as colorless oil $(90 \%$ yield) from $\beta$-thioglucose and $p$-hydroxyanisole according to an already published protocol ${ }^{[14 a]}$. Characterization data were identical with those already described.

Enzymatic thioglycosylation: General procedure 1: $p$-nitrophenyl-ß-Dglycopyranoside (1.0 equiv., $40 \mathrm{mg}$ ) and 20 equiv. of aminothiophenol were dissolved in Tris-Base/Tris $\mathrm{HCl}$ buffer $(20 \mathrm{mM}, \mathrm{pH} 9,2 \mathrm{~mL})$. Thioglycoligase mutant DtGly E159Q (80 nmol, 1.10-4 equiv.) was successively added and the mixture was stirred at room temperature overnight. Reaction was concentrated under reduced pressure and then purified by flash chromatography.

p-aminophenyl-ß-D-thioglucopyranoside ( $S$-1) was obtained using $p$ nitrophenyl- $ß-D-$ glucopyranoside $(0.13 \mathrm{mmol}, 1.0$ equiv.) according to the general procedure 1 . The desired compound was obtained after flash chromatography (DCM/MeOH 9/1) as a white solid (38 mg, $99 \%$ ). ${ }^{1} \mathrm{H} \mathrm{NMR}$ $\left(\mathrm{D}_{2} \mathrm{O}, 400 \mathrm{MHz}\right) \delta: 7.44(2 \mathrm{H}, \mathrm{d}, \mathrm{J}=8.4 \mathrm{~Hz}, \mathrm{H}-8), 6.85(2 \mathrm{H}, \mathrm{d}, \mathrm{J}=8.4 \mathrm{~Hz}$, $\mathrm{H}-9), 4.57(1 \mathrm{H}, \mathrm{d}, \mathrm{J}=10.0 \mathrm{~Hz}, \mathrm{H}-1), 3.89(1 \mathrm{H}, \mathrm{dd}, \mathrm{J}=1.6,12.4 \mathrm{~Hz}, \mathrm{H}-6)$, $3.72(1 \mathrm{H}, \mathrm{dd}, \mathrm{J}=5.6,12.4 \mathrm{~Hz}, \mathrm{H}-6$ ') $3.51(1 \mathrm{H}, \mathrm{t}, \mathrm{J}=8.8 \mathrm{~Hz}, \mathrm{H}-3), 3.42(2 \mathrm{H}$, $\mathrm{m}, \mathrm{H}-4, \mathrm{H}-5), 3.27(1 \mathrm{H}, \mathrm{t}, \mathrm{J}=9.6 \mathrm{~Hz}, \mathrm{H}-2) .{ }^{13} \mathrm{C}$ NMR $\left(\mathrm{D}_{2} \mathrm{O}, 100 \mathrm{MHz}\right) \delta$ : 147.38 (C10), 135.36 (C8), 118.99 (C7), 116.67 (C9), 87.98 (C1), 79.85 (C4), 77.23 (C3), 71.51 (C2), 69.36 (C5), 60.52 (C6). HRMS (m/z) [M+Na]+ calculated for $\mathrm{C}_{12} \mathrm{H}_{17} \mathrm{NNaO}_{5} \mathrm{~S} 310.07196$; found 310.07207 .

p-aminophenyl-ß-D-thiogalactopyranoside (S-2) was obtained using $p$ nitrophenyl-ß-D-galactopyranoside $(0.13 \mathrm{mmol}, 1.0$ equiv.) according to the general procedure 1. The desired compound was obtained after flash chromatography $(\mathrm{DCM} / \mathrm{MeOH}, 9: 1)$ as a white solid $(30 \mathrm{mg}, 79 \%) .{ }^{1} \mathrm{H}$ NMR (CD $\left.{ }_{3} \mathrm{OD}, 400 \mathrm{MHz}\right)$ ס: $7.34(2 \mathrm{H}, \mathrm{d}, \mathrm{J}=7.2 \mathrm{~Hz}, \mathrm{H}-8), 6.63(2 \mathrm{H}, \mathrm{d}, \mathrm{J}=$ $7.6 \mathrm{~Hz}, \mathrm{H}-9), 4.31(1 \mathrm{H}, \mathrm{d}, \mathrm{J}=9.2 \mathrm{~Hz}, \mathrm{H}-1), 3.86(1 \mathrm{H}, \mathrm{s}, \mathrm{H}-4), 3.71(2 \mathrm{H}, \mathrm{m}$, $\mathrm{H}-6), 3.51(1 \mathrm{H}, \mathrm{t}, \mathrm{J}=9.6 \mathrm{~Hz}, \mathrm{H}-2), 3.46(2 \mathrm{H}, \mathrm{m}, \mathrm{H}-3, \mathrm{H}-5) .{ }^{13} \mathrm{C} \mathrm{NMR}\left(\mathrm{CD}_{3} \mathrm{OD}\right.$, $100 \mathrm{MHz}$ ) ס: 149.48 (C10), 136.30 (C8), 120.89 (C7), 116.44 (C9), 91.62 (C1), 80.46 (C5), 76.39 (C3), 70.98 (C2), 70.43 (C4), 62.54 (C6). HRMS $(\mathrm{m} / \mathrm{z})[\mathrm{M}+\mathrm{Na}]+$ calculated for $\mathrm{C}_{12} \mathrm{H}_{17} \mathrm{NNaO}_{5} \mathrm{~S} 310.07196$; found: 310.07159

p-aminophenyl-ß-D-thiofucopyranoside (S-3) was obtained using $p$ nitrophenyl-ß-D-fucopyranoside $(0.14 \mathrm{mmol}, 1.0$ equiv.) according to the general procedure 1 . The desired compound was obtained after flash chromatography $(\mathrm{DCM} / \mathrm{MeOH}, 9: 1)$ as a white solid $(20 \mathrm{mg}, 52 \%) .{ }^{1} \mathrm{H}$ NMR (CD $\left.{ }_{3} \mathrm{OD}, 400 \mathrm{MHz}\right) \delta: 7.31(2 \mathrm{H}, \mathrm{d}, \mathrm{J}=8.0 \mathrm{~Hz}, \mathrm{H}-8), 6.64(2 \mathrm{H}, \mathrm{d}, \mathrm{J}=$ $8.0 \mathrm{~Hz}, \mathrm{H}-9), 4.28(1 \mathrm{H}, \mathrm{d}, \mathrm{J}=8.4 \mathrm{~Hz}, \mathrm{H}-1), 3.56(1 \mathrm{H}, \mathrm{s}, \mathrm{H}-4), 3.56(1 \mathrm{H}, \mathrm{q}$, $\mathrm{J}=6.4 \mathrm{~Hz}, \mathrm{H}-5), 3.46(2 \mathrm{H}, \mathrm{m}, \mathrm{H}-2, \mathrm{H}-3), 1.24(3 \mathrm{H}, \mathrm{d}, \mathrm{J}=6.4 \mathrm{~Hz}, \mathrm{H}-6) .{ }^{13} \mathrm{C}$ 
NMR (CD $\left.{ }_{3} \mathrm{OD}, 100 \mathrm{MHz}\right) \delta: 149.93$ (C10), 136.81 (C8), 121.44 (C7), 116.88 (C9), 91.95 (C1), 76.93 (C2), 76.38 (C5), 73.60 (C4), 71.28 (C3), 17.42 (C6). HRMS (m/z) $[\mathrm{M}+\mathrm{Na}]+$ calculated for $\mathrm{C}_{12} \mathrm{H}_{17} \mathrm{NNaO}_{4} \mathrm{~S}$ 294.07705; found 294.07693

\section{Chemical synthesis of the O-glycosidic series}

p-aminophenyl- $ß-D-g l u c o p y r a n o s i d e(\boldsymbol{O}-1)$ was synthesized as a white solid ( $97 \%$ yield) from $p$-nitrophenyl- $ß-D-$ glucopyranoside according to an already published protocol[23]. Characterization data were identical with those already described.

p-aminophenyl- $ß$-D-galactopyranoside (O-2) was synthesized as a white solid ( $91 \%$ yield) from $p$-nitrophenyl- $B-D-$ galactopyranoside according to an already published protocol[ ${ }^{[23]}$. Characterization data were identical with those already described.

p-aminophenyl- $ß-D-f u c o p y r a n o s i d e(O-3)$ was synthesized as a white solid ( $97 \%$ yield) from $p$-nitrophenyl- $ß-D$-fucoopyranoside according to an already published protocol[ ${ }^{[23]}$. Characterization data were identical with those already described.

\subsection{Biological procedures}

\section{Protein expression and purification}

Production and purification of DtGlyE159Q was performed as described previously by Guillotin et a/ ${ }^{[19]}$. Escherishia coli Rosetta (DE3) transformed with expression plasmids were grown in LB medium supplemented with chloramphenicol $(34 \mu \mathrm{g} / \mathrm{mL})$ and kanamycin $(30 \mu \mathrm{g} / \mathrm{mL})$ at $37{ }^{\circ} \mathrm{C}$ until OD600 reached 0.6 . Induction was then done by addition of $1 \mathrm{mM}$ IPTG and incubated overnight a $25^{\circ} \mathrm{C}$. Cells were harvested, lyzed by freezethaw cycles and sonication. Then, supernatant was clarified by heat treatment for $15 \mathrm{~min}$ at $70{ }^{\circ} \mathrm{C}$ before centrifugation. Finally, supernatant was loaded on a Nickel column (HisPure, Thermo Scientific) and purified by elution with lysis buffer containing $500 \mathrm{mM}$ imidazole. The concentration of the various fractions collected was obtained by Bradford assay.

\section{Lectin Array assays}

Lectin Array assays were performed according GlycoDiag's protocol already described ${ }^{[25]}$. Briefly, GLYcoPROFILEs were performed on LEctPROFILE $®$ plates from GLYcoDiag (Orléans, France). The interaction profiles of each compound were determined through an indirect method based on the inhibition by the compound of the interaction between a specific couple lectin-glycan (neoglycoproteins or glycoproteins). Briefly, a mix of neoglycoproteins or glycoproteins (fixed concentration) and the corresponding compounds (range of concentrations) prepared in PBS supplemented with $1 \mathrm{mM} \mathrm{CaCl} 2$ and 0.5 $\mathrm{mM} \mathrm{MgCl} 2$ is deposed in each well $(50 \mu \mathrm{L}$ each) in triplicates and incubated two hours at room temperature. After washing with PBS buffer, the conjugate streptavidine-DTAF for fluorescence plate or extravidineperoxydase for absorbance palte is added $(50 \mu \mathrm{L})$ and incubated $30 \mathrm{~min}$ more. The plate was washed again with PBS. Finally, $100 \mu \mathrm{L}$ of PBS was added for the readout of fluorescent plate performed with a fluorescence reader $(\lambda e x=485 \mathrm{~nm}, \lambda \mathrm{em}=530 \mathrm{~nm}$, Fluostar OPTIMA, BMG LABTECH,France) For the absorbance plate, the plate was washed with PBS buffer, and a solution of OPD (SIGMAFAST ${ }^{\mathrm{TM}}$ OPD (oPhenylenediamine dihydrochloride), $100 \mu \mathrm{l}$ ) for the detection of the peroxidase activity. The plate was incubated 15 min protected from light. The coloration was stopped by adding $\mathrm{HCl}(100 \mu \mathrm{l}, 1 \mathrm{mM})$ and the readout performed with an absorbance reader. The signal intensity is inversely correlated with the capacity of the compound to be recognized by the lectin and expressed as inhibition percentage with comparison with the corresponding tracer alone (Neoglycoproteins or glycoproteins).

\section{NeoPROFILE@ Assays}

NeoPROFILE@ Assays were performed according GlycoDiag's protocol already described ${ }^{[26]}$. Compounds interactions with carbohydrate recognition receptors expressed at the surface of NHEK cells were measured and achieved with fluoresceinylated neoglycoproteins according to GLYcoDiag technology. ( $\alpha-G$ alactose-BSA, ß-Glucose-BSA, $\alpha$-Rhamnose-BSA). Briefly, cells were first grown to confluence (80-90\%) in 96-well plates. Once the confluence reaches, cells were washed several times with PBS and incubated with fluorescent neoglycoproteins (fixed concentrations) and compounds (range of concentrations) and incubated $4 \mathrm{~h}$ at $4{ }^{\circ} \mathrm{C}$. Then, the plates were carefully rinsed with PBS. $200 \mathrm{uL}$ of fresh PBS was added for the fluorescence readout $(\lambda e x=485 \mathrm{~nm}, \lambda$ em $=530$ $\mathrm{nm}$ ). The amount of neoglycoproteins stayed in interaction with cells was compared with the amount of neoglycoprotein in absence of product.

\section{Tyrosinase inhibition tests}

Tyrosinase inhibitor activity was measured by spectrophotometry based one the method presented by Masamoto et al[24]. $10 \mu \mathrm{L}$ of inhibitor solution at different concentrations in DMSO were placed into 96-wells microplate mixed with ammonium formate buffer $(60 \mu \mathrm{L}, 50 \mathrm{mmol} / \mathrm{L}, \mathrm{pH} 6.4)$ and 20 $\mu \mathrm{L}(0.8 \mathrm{mg} / \mathrm{mL})$ of tyrosine was added. Just before the absorbance read at $450 \mathrm{~nm}, 10 \mu \mathrm{L}$ of mushroom tyrosinase $(5000 \mathrm{U} / \mathrm{mL})$ was added. The mixture was incubated at $27{ }^{\circ} \mathrm{C}$ for $10 \mathrm{~min}$. The absorbance value was recovered every $20 \mathrm{sec}$ during $10 \mathrm{~min}$. Arbutine were used as a positive control. Each measurement was performed at least in triplicate. The IC50, corresponding to the needed concentration to observe $50 \%$ loss of the enzyme activity, were calculated with GraphPad.

\section{Acknowledgements}

The authors thank the regions Centre Val de Loire and Bretagne for their financial support

Keywords: Arbutin analogs $\cdot$ Carbohydrates $\cdot$ Enzyme Catalysts $\cdot$ Thioglycoligase $\cdot$ Whitening Agent

a) S. Kunachak, P. Leelaudomlipi, S. Wongwaisayawan, Aesthetic Plast Surg 2001, 25, 114-117; b) B. R. Nelson, D. J. Fader, M. Gillard, S. R. Baker, T. M. Johnson, J Am Acad Dermatol 1995, 32, 623-626; c) K. B. Penney, C. J. Smith, J. C. Allen, J Invest Dermatol 1984, 82, 308-310; d) Y. Kobayashi, H. Kayahara, K. Tadasa, T. Nakamura, H. Tanaka, Biosci., Biotechnol., Biochem. 1995, 59, 17451746.

[2] a) M. Seiberg, C. Paine, E. Sharlow, P. Andrade-Gordon, M. Costanzo, M. Eisinger, S. S. Shapiro, J. Invest. Dermatol. 2000, 115, 162-167; b) A. Greatens, T. Hakozaki, A. Koshoffer, H. Epstein, S. Schwemberger, G. Babcock, D. Bissett, H. Takiwaki, S. Arase, R. R. Wickett, R. E. Boissy, Exp. Dermatol. 2005, 14, 498-508.

[3] a) A. Palumbo, M. d'Ischia, G. Misuraca, G. Prota, Biochim Biophys Acta 1991, 1073, 85-90; b) K. Jimbow, H. Obata, M. A. Pathak, T. B. Fitzpatrick, J Invest Dermatol 1974, 62, 436-449.

[4] a) W. Westerhof, T. J. Kooyers, J Cosmet Dermatol 2005, 4, 55-59; b) J. J. Nordlund, P. E. Grimes, J. P. Ortonne, J Eur Acad Dermatol Venereol 2006, 20, 781-787.

[5] a) C. Ramírez, K. Pham, M. F. E. Franco, M. Chwa, A Limb, B. D. Kuppermann, M. C. Kenney, NeuroToxicology 2013, 39, 102-108; b) G. H. Kim, K. A. Cheong, A.-Y. Lee, Ann Dermatol 2017, 29, 715-721.

[6] G. N. Selezenev, D. M. Popov, N. G. Selezenev, Vopr. Biol., Med. Farm. Khim. 2012, 18-21.

[7] Y.-J. Lim, E. H. Lee, T. H. Kang, S. K. Ha, M. S. Oh, S. M. Kim, T.-J. Yoon, C. Kang, J.-H. Park, S. Y. Kim, Arch. Pharmacal Res. 2009, 32, 367-373.

[8] a) M. Seiberg, Pigm. Cell Res. 2001, 14, 236-242; b) D. Cerdan, G. Redziniak, C. A. Bourgeois, M. Monsigny, C. 
Kieda, Exp. Cell Res. 1992, 203, 164-173; c) R. E. Boissy, Exp Dermatol 2003, 12 Suppl 2, 5-12.

[9] a) K. Sugimoto, T. Nishimura, K. Nomura, K. Sugimoto, T. Kuriki, Chem. Pharm. Bull. 2003, 51, 798-801; b) A. Garcia-Jimenez, J. A. Teruel-Puche, J. Berna, J. N. Rodriguez-Lopez, J. Tudela, F. Garcia-Canovas, PLoS One 2017, 12, e0177330; c) R. E. Boissy, M. Visscher, M. A. de Long, Exp. Dermatol. 2005, 14, 601-608.

[10] M. Qiao, L. Zhang, R. Jiao, S. Zhang, B. Li, X. Zhang, Tetrahedron 2021, 81, 131920.

[11] a) H. Driguez, ChemBioChem 2001, 2, 311-318; b) D. J. Wardrop, S. L. Waidyarachchi, Nat. Prod. Rep. 2010, 27, 1431-1468; c) C. S. Rye, S. G. Withers, Carbohydr. Res. 2004, 339, 699-703; d) T. Belz, Y. Jin, J. Coines, C. Rovira, G. J. Davies, S. J. Williams, Chem. Commun. (Cambridge, U. K.) 2017, 53, 9238-9241.

[12] C.-F. Liang, M.-C. Yan, T.-C. Chang, C.-C. Lin, J. Am. Chem. Soc. 2009, 131, 3138-3139.

[13] a) P. Ramrao Patil, K. P. Ravindranathan Kartha, Green Chem. 2009, 11, 953-956; b) S. Escopy, Y. Singh, A. V. Demchenko, Org. Biomol. Chem. 2019, 17, 8379-8383.

[14] a) E. Brachet, J. D. Brion, M. Alami, S. Messaoudi, Chemistry 2013, 19, 15276-15280; b) A. Bruneau, M. Roche, A. Hamze, J. D. Brion, M. Alami, S. Messaoudi, Chemistry 2015, 21, 8375-8379.

[15] I. Cepanec, M. Litvic, ARKIVOC (Gainesville, FL, U. S.) 2008, 19-24.

[16] H. Zhou, J. Zhao, A. Li, M. T. Reetz, Molecules 2019, 24, 3303.

[17] M. Jahn, J. Marles, R. A. J. Warren, S. G. Withers, Angew. Chem., Int. Ed. 2003, 42, 352-354.

[18] J. Mullegger, H.-M. Chen, W. Y. Chan, S. P. Reid, M. Jahn, R. Antony, J. Warren, H. M. Salleh, S. G. Withers, ChemBioChem 2006, 7, 1028-1030.

[19] L. Guillotin, Z. Assaf, S. G. Pistorio, P. Lafite, A. V. Demchenko, R. Daniellou, Catalysts 2019, 9, 826.

[20] a) A. Usuki, A. Ohashi, H. Sato, Y. Ochiai, M. Ichihashi, Y. Funasaka, Exp Dermatol 2003, 12 Suppl 2, 43-50; b) H.

Shimogaki, Y. Tanaka, H. Tamai, M. Masuda, Int J Cosmet Sci 2000, 22, 291-303; c) I. Hori, K. Nihei, I. Kubo, Phytother Res 2004, 18, 475-479.

[21] L. Guillotin, P. Lafite, R. Daniellou, Carbohydr. Chem. 2014, 40, 178-194.

[22] J. Wei, X. Lv, Y. Lue, G. Yang, L. Fu, L. Yang, J. Wang, J. Gao, S. Cheng, Q. Duan, C. Jin, X. Li, Eur. J. Org. Chem. 2013, 2013, 2414-2419.

[23] C. Peyrot, T. Vives, L. Legentil, L. Lemiegre, R. Daniellou, ChemistrySelect 2017, 2, 5214-5217.

[24] Y. Masamoto, H. Ando, Y. Murata, Y. Shimoishi, M. Tada, K. Takahata, Biosci., Biotechnol., Biochem. 2003, 67, 631634.

[25] L. Landemarre, E. Duverger, Methods Mol. Biol. (N. Y., NY, U. S.) 2013, 988, 221-226.

[26] a) L. Landemarre, P. Cancellieri, E. Duverger, Glycoconj J 2012, 30, 195-203; b) H. Ozanne, H. Toumi, B. Roubinet, L. Landemarre, E. Lespessailles, R. Daniellou, A. Cesaro, Cosmetics 2020, 7. 
WILEY-VCH

FULL PAPER

\section{Entry for the Table of Contents}

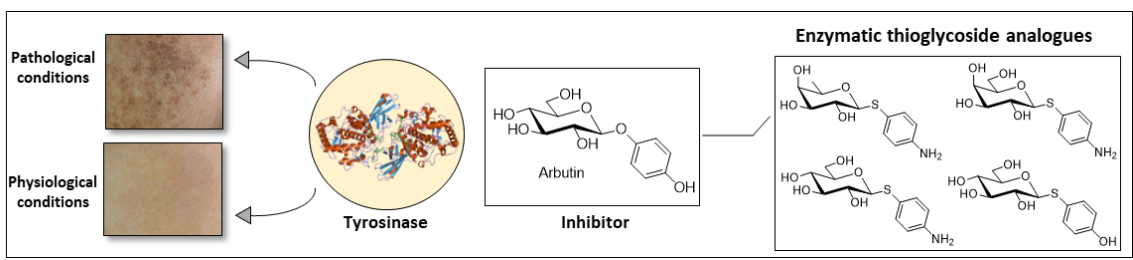

A biocatalyzed synthesis led to the preparation of a series of thioglycoside analogs of arbutin. These original molecules demonstrated potent tyrosinase inhibition properties, as well as the capacity to interact with lectins at the surfaces of cells. The presence of the sulfur atom prove therefore to increase the biological potency of these glycosides.

Institute and/or researcher Twitter usernames: daniellou_r 